BMJ Paediatrics Open

\section{Using the internet to cope with chronic fatigue syndrome/myalgic encephalomyelitis in adolescence: a qualitative study}

To cite: Brigden A, Barnett J, Parslow RM, et al. Using the internet to cope with chronic fatigue syndrome/ myalgic encephalomyelitis in adolescence: a qualitative study. BMJ Paediatrics Open 2018;2:e000299. doi:10.1136/ bmjpo-2018-000299

- Additional material is published online only. To view please visit the journal online (http://dx.doi.org/10.1136/ bmjpo-2018-000299).

RMP and LB contributed equally.

Received 10 April 2018 Accepted 22 May 2018

Check for updates

\section{(c) Author(s) (or their} employer(s)) 2018. Re-use permitted under CC BY-NC. No commercial re-use. See rights and permissions. Published by BMJ.

${ }^{1}$ Centre for Child and Adolescent Health, Bristol Medical School, University of Bristol, Bristol, UK ${ }^{2}$ Department of Psychology, University of Bristol, Bristol, UK

Correspondence to Miss Amberly Brigden; amberly. brigden@bristol.ac.uk

\section{ABSTRACT}

Background Adolescents are increasingly using online resources for health purposes. Previous studies suggest that online provision of information about chronic fatigue syndrome or myalgic encephalomyelitis (CFS/ME) is neither balanced nor consistent with evidence-based practice. However, little is known about how adolescents with CFS/ $\mathrm{ME}$ use the internet for their condition and whether this is helpful or harmful.

Methods Nine indepth, semistructured, qualitative interviews were conducted with young people (aged 12-17) recruited from a specialist paediatric CFS/ME service. Interviews explored the types of online resources accessed, motivations for doing so and how resource use related to patterns of coping.

Results Around the time of diagnosis, participants focused on gathering facts about CFS/ME and therefore used official resources (eg, National Health Service sites) that were considered reliable. This transitioned to exploring patient-led and peer-led spaces: health forums, Facebook and YouTube. Participants accessed these regularly, over the long term, and valued these sites for the personal stories, emotional content and interactive technology. Patient-led and peer-led sites supported coping, encouraging active behavioural management, providing social support and addressing stigmatised aspects of the condition. CFS/ME put a strain on normal adolescent life, such as identity and friendships. Online resources allowed participants to adapt and maintain a sense of normality. Conclusions Adolescents who use the internet find online resources helpful in seeking information and social support for their condition. Healthcare services should improve their online resources to meet the needs of younger users, providing evidence-based content in ways that are relevant to adolescents and that can meet the needs for social support, as well as providing information.

\section{INTRODUCTION}

Paediatric chronic fatigue syndrome/ myalgic encephalomyelitis (CFS/ME) is relatively common, ${ }^{1-4}$ and is characterised by persistent and disabling fatigue accompanied by other symptoms such as pain and cognitive dysfunction. ${ }^{5}$ Paediatric CFS/ME

\section{What is already known on this topic?}

Paediatric chronic fatigue syndrome or myalgic encephalomyelitis (CFS/ME) is relatively common and disabling, with significant impact on the individual, family and health services.

- Adolescents are increasingly going online for health purposes. Online resources can be beneficial in providing social support. However, disadvantages include misleading or inaccurate medical information.

- Previous studies suggest that online provision of information about CFS/ME is neither balanced nor consistent with evidence-based practice.

\section{What this study hopes to add?}

Participants initially focused on official resources (eg, National Health Service sites) for fact-finding. This transitioned to patient/peer -led, which were accessed regularly and over the long-term.

- Patient-led/peer-led sites supported coping; they encouraged active behavioural management, provided social support, addressed stigmatised aspects of the condition and helped maintain normal adolescent life.

- Feeling connected to other adolescents with the condition was important, and online forums addressed this need; accessing such forums complemented treatment with specialist CFS/ME services.

affects physical, emotional and cognitive development, disrupting friendships, family, schooling and hobbies at a particularly vulnerable time of life. ${ }^{6-9}$

While we know that young people are going online for health purposes, ${ }^{10}$ we do not know the impact of this on adolescents with CFS/ME. Many online spaces have no form of expert moderation and so may provide misleading or inaccurate medical information. $^{12}$ Early studies concluded that the online material about CFS/ME was neither balanced nor consistent with 
evidence-based practice. ${ }^{13} 14$ This is compounded by the difficulties that adolescents report in assessing online information and knowing which sites to trust. ${ }^{15}$ On the other hand, the extent to which adolescents cope with a chronic illness is associated with psychological well-being, health behaviours and health outcomes, ${ }^{16-18}$ and online resources may enhance coping. The internet provides the opportunity for adolescents to confidentially and conveniently access health information. ${ }^{19}$ The ability to connect with others with health conditions provides opportunity for self-disclosure, social support, empathy, reduced isolation, sharing of personal experiences and empowerment. ${ }^{20-25}$ These conflicting findings, and the associated uncertainty about the potential impact of accessing online resources on patients' responses to their condition, may underpin clinicians' reluctance in accepting the internet as a resource for their patients. ${ }^{2627}$

This study aimed to gather the views of adolescents with CFS/ME to explore what they access online for information and support, and how this influences the way they cope with their condition.

\section{METHODS}

Participants, sampling and recruitment

Participants were recruited from a specialist paediatric CFS/ME service. Adolescents were eligible if they had a diagnosis of $\mathrm{CFS} / \mathrm{ME},{ }^{5}$ were aged $12-17$ years and self-identified as having used the internet for CFS/ME. Adolescents were excluded if they had insufficient proficiency in the English language to participate in an interview or if they were severely affected ${ }^{5}$ (as we felt there was a risk that the interview might make symptoms worse). Clinicians screened patients for eligibility, offered information sheets and took consent/assent to contact. The researcher contacted interested participants, and interviews were arranged at a time and location convenient to the participant (home, clinic or Skype). Written valid informed consent/assent was obtained prior to the interview. The interviewer was not previously known to the participant, and was independent of the clinical team that the participant was receiving treatment from.

Sampling was opportunistic insofar as it recruited eligible participants who were willing and able to take part. Recruitment ended when it was felt there was enough quality data to answer the research question, within the constraints of the study. Sample size was guided by the principle of 'information power' ${ }^{28}$ and was reviewed during the process of analysis. Information power deems that smaller numbers are justifiable if the research question is narrow, if the sample is more homogeneous and if there is a good-quality dialogue.

\section{Topic guide}

The topic guide (online supplementary appendix) was developed to answer the research questions, in line with the literature on coping. The questions were open-ended to ensure answers were not unduly constrained. The topic guide was piloted with a member of the CFS/ME patient advisory group.

The interviewer was completing an MSc in Health Psychology which covered qualitative methods. Practical training and guidance were provided through supervision and guidance around the development of the topic guide, as well as interviewing style.

\section{Procedure}

Participants were interviewed alone or with a parent/ carer depending on the participant's preference (see table 1). The semistructured topic guide was used, and participants were encouraged to talk for as long as they needed. Interviews were audio-recorded, transcribed verbatim and anonymised. Initially transcripts were read to become familiar with the data, and thematic analyses were carried out using the stages proposed by Braun and Clarke $^{29}(\mathrm{AB})$. Four transcripts were double-coded (LB, RMP), and two senior researchers collaborated on the development of themes and interpretations $(\mathrm{EC}, \mathrm{JB})$.

As there was limited research in the area, we began by developing codes in an inductive manner. The process

\begin{tabular}{llllll}
\hline \multicolumn{2}{l}{ Table 1} & \multicolumn{2}{l}{ Participant demographics and clinical characteristics } \\
\hline Participant ID & Gender & Age at interview & $\begin{array}{l}\text { Months from initial } \\
\text { assessment to interview }\end{array}$ & $\begin{array}{l}\text { Severity: \% of school attended at } \\
\text { time of assessment }\end{array}$ & Parent/carer present \\
\hline 1 & Female & $15-17$ & 11 & 30 & Yes \\
2 & Female & $12-14$ & 4 & 60 & Yes \\
\hline 3 & Male & $15-17$ & 19 & 0 & No \\
4 & Female & $15-17$ & 25 & 0 & No \\
\hline 5 & Female & $15-17$ & 24 & 0 & No \\
6 & Female & $15-17$ & 4 & NA & No \\
\hline 7 & Male & $15-17$ & 9 & 40 & Yes \\
8 & Female & $12-14$ & 8 & 40 & Yes \\
\hline 9 & Male & $12-14$ & 12 & 0 &
\end{tabular}

NA, not available. 
of theme development was informed by the literature on coping.

\section{RESULTS}

\section{Participant characteristics}

Data were collected between May 2015 and July 2016. There were nine participants; all identified as white British and six $(66.6 \%)$ were female. The mean age was 14.89 (SD 1.9). Participants were at different stages of the condition; the mean number of months from initial assessment to interview was 12.89 months (SD 7.98), with a range of 4 months to 25 months (see table 1 for participant demographics and clinical characteristics).

\section{Themes}

\section{Theme 1: using digital resources to meet changing needs}

Around the time of diagnosis participants sought out "official" (P5) sites to establish facts about the condition. Participants explicitly talked about an intention to factfind, with references to carrying out "research" (P5) and "to know more about it" (P2). This was also indicated by the nature of the sites visited; participants talked about their status as "reliable" (P1, P3, P7). For the majority, this included National Health Service (NHS) websites, and in some cases it also included Action for ME, Association of Young People with ME/Chronic Fatigue and the ME Association (CFS/ME charities).

P1: the NHS are the ones that you can trust more... you know that they're like safe to be reading, like with the information you know it's probably going to be true.

Some participants indicated that reading the facts about symptoms was helpful; they identified with the information and felt validated by this. Some participants felt there was not enough information about treatments.

Participants felt that the NHS sites were not userfriendly; they used medical terminology, lacked depth and were static - the content remained unchanged.

P4: I've had a look on the NHS site...it's quite wordy and that sort of thing I wouldn't necessarily understand...it's sort of doctorised...it's not necessarily aimed at young people.

A common pattern was that participants only used the NHS sites a few times.

Most participants moved on to explore patient-led and peer-led sites containing subjective, experiential accounts.

P3: It was like personal experiences of people who have had the illness, and it was nice to read something from someone like similar to yourself, knowing that goes through the same thing day in and day out.

This included health forums, but also sites that were not necessarily health-related, including Facebook,
Instagram, Blogs and YouTube. Only one participant did not report accessing these types of sites.

Participants who used these sites were positive about them, using words such as "hope" (P7, $\mathrm{P} 9)$, "reassuring" (P1), "motivating" (P3) and "boost" (P9). The majority of participants did not highlight the potential negatives, such as reading personal stories of suffering. This tended to be a marginal part of the experience and participants employed strategies to manage negatives.

P7: you stumble on some few very dark ones you just have to brush those off cause there's not a lot of cases that you'll find those, but they're a bit depressing when you do. You have to keep to the bright ones that tell you how to work with it you've got to stick with the ones which aren't so depressing.

In contrast to NHS sites, patient-led/peer-led sites were accessed regularly and over the long-term, such as "a few times a week" (P3) or "every day" (P2). These sites used ingroup terms and phrases which were accessible and appealing. They were considered to offer a greater level of depth and were constantly updated. Participants preferred this story-telling approach, the numerous accounts and the technological affordances of videos.

P7: [YouTube] was a really nice way of explaining it, you got more of a personal touch to it because you saw people and then you saw in the comments of YouTube videos...that made me feel quite good to like watch them even, not have to like scroll through, I could just sit down and watch YouTube videos. Yeah it was good.

\section{Theme 2: using digital resources to enhance coping}

Although a few participants reported reading about self-management approaches on official websites, for most participants it was the patient-led/peer-led sites that were associated with coping.

\section{Behavioural coping}

Participants reported that forums were spaces where participants could learn about coping strategies from others. Strategies included establishing sleep routines, activity management, pacing, meditation, supplementing schooling with online education, taking exams at home and methods to monitor activity.

As well as learning about strategies, anecdotes and endorsements appeared to promote beliefs in the efficacy of strategies, providing the inspiration to try out the strategies.

P3: reading other people's stories saying that they've been able to get up and do something have a good day it's kind of motivating knowing that if someone else can do it then you can to... (text missing) thinking oh wait if they can do that and it helped them then maybe it may help me and maybe I should try that and hopefully it might work for me as well. 
One participant linked the active behavioural coping strategies supported by the forums to improved outcomes.

P6: (forum) really helped me to overcome being tired and stuff like that and I would take on board the tips.

\section{Social support for coping}

Participants described the loneliness of the condition. Through spending time on these sites, they developed "connection" (P3) with others and a sense of "community" (P5, P9), which alleviated this isolation. They experienced a sense of being able to relate to others like them and feeling understood and validated.

P5: in life with ME like I am now, you kind of feel alone...but when you go on the website you suddenly feel like part of the community you don't feel like you're the only one with ME...it's nice cause you don't feel alone.

Certain technological affordances were described as facilitating a sense of relationship. The fact that these sites could be rapidly accessed at any time seemed to provide a great sense of support. Participants stated they could interact with these sites in a quick and undemanding way through a shared language of 'likes' and 'comments'. More generally, the online world was less demanding and more flexible than offline relationships especially in the context of a disabling and fluctuating illness.

P5: it's just the support knowing that at any time during the day if I'm having a bad day I can literally go on and I know immediately I'll have support.

P5: it's more nerve wracking meeting face to face because it's the physical side of it...I'm on crutches you have the pressure on you from that...but if you're talking on the internet you don't have to worry about anything like physically...you don't have to put your make up on...you don't have to worry about yourself and if you're having a bad day it's easy to sit on your bed on your phone.

\section{Coping with stigmatised aspects of the condition online and offline}

Several participants raised the issues of comorbid psychological difficulties, such as anxiety and low mood, and the support that the sites provided. Some participants indicated that these were difficult subjects to talk about with family, friends and clinicians, but that it was therapeutic to engage with this material online. Participants explained that reading stories online encouraged them to open up and seek help offline.

P6: because when I was also diagnosed with anxiety and $\mathrm{OCD}$ as well as $\mathrm{ME}$, going online and reading about other people and how they cope with it did really help me to speak up especially to my family and [clinician]...so it did really open up my views on mental health and how I coped with stuff like that.
Theme 3: providing normality

Participants reported that CFS/ME put a strain on normal adolescent life, such as their identity and friendships. The digital spaces allowed them to adapt and maintain normality.

Participants used the internet to explore their condition; however, these supportive spaces were also places where they could explore and maintain aspects of identity unrelated to their condition. They talked about and connected with others about typical adolescent hobbies and things that defined them unrelated to CFS/ME.

P9: they [Facebook support group] talk about if they have a particularly bad day or a particularly good day....and then we just talk about stuff like video games and like dogs and stuff like that just like normal things so it's a bit of both and it's just a really nice community.

Participants also talked about the role of the internet in relation to supporting offline friendships. Lack of understanding and invalidation from friends was discussed, but individuals talked about showing their friends online information to legitimise their illness and help their peers understand and adapt to the illness.

P8: Oh yeah I showed some of my friends [a website] so that they could understand a bit more .... and it meant that they could try and adapt...I was happy that I could show it [website] to my friends...you will see that it a real thing and not something that I've just gone oh yeah I have got something called Chronic Fatigue but I'm actually just really tired that was definitely one useful thing.

\section{DISCUSSION}

\section{Summary of findings}

This is the first study to explore what young people with CFS/ME access online for their health condition and their views on the impact this has on coping with CFS/ME. Participants used official sites (such as NHS websites) for a limited time at the start of their illness for fact-finding. However, they used patient-led/peer-led sites more frequently and over a longer period of time. These supported coping: encouraging active behavioural management; providing social support; addressing stigmatised aspects of the condition; and providing a sense of normality in the face of an isolating and disabling condition.

\section{Strengths and limitations}

The strengths of this study included allowing participants to express their own views and provide a rich detailed account of their experiences, relatively unconstrained by prior concepts. ${ }^{29}$ The sample size is small, and a larger sample may have added richer data to themes and may have also allowed for greater exploration of deviant cases. However, the reported themes were clearly identified, 
and the results should therefore be considered as a valid base on which to build further investigation. Participants classified themselves as white British, and therefore the findings may not apply to other ethnic backgrounds. Participants were recruited from a specialist CFS/ME service; those who chose not to or who are unable to access specialist treatment may use the internet differently.

The power balance, age dynamic and, in some cases, presence of a parent/carer could have meant that the adolescents may have felt discouraged from sharing certain behaviours and experiences with an adult, for fear of disapproval, shame or embarrassment. However, the interviewer was independent from the clinical team, aimed to employ active listening skills, build rapport and come from non-judgemental and validating standpoint. This may have created an environment where participants felt able to provide richer and more personal information, for example opening up about psychological experiences. This idea reflects previous qualitative work exploring the views of adolescents with CFS/ME. ${ }^{30}$

These results are consistent with the literature. ${ }^{31}{ }^{32} \mathrm{~A}$ meta-synthesis exploring the experiences of living with a chronic illness during adolescence concluded that the most important themes were developing and maintaining friendships and being normal/getting on with life. ${ }^{33}$ A chronic disease can make these development milestones especially trying. ${ }^{34}$ Adolescents with chronic illnesses benefit from forming friendships with other young people with the same condition because they are sharing the same life experiences and do not have to keep secrets or hide visible differences. ${ }^{35} 36$ These therapeutic effects can be fostered through online support groups, with benefits including social support, empathy from others, reduced isolation and the opportunity to share personal experiences. ${ }^{24}$

\section{Implications}

Adolescents are likely to visit official sites in search of reliable information. Health services should offer online information that is meaningful and engaging to younger users. Content could be improved by providing information that is important to young people: symptoms, treatments and ways to explain the condition to peers. Content could also be improved by providing a greater depth of information; using story-telling and patient vignettes; and ensuring language is age-appropriate. Incorporating technological affordances, for example videos and interactive interfaces, may also be beneficial. With interest in e-treatments for paediatric CFS/ME, ${ }^{37}{ }^{38}$ this study indicates that perceptions of a supportive relationship (an important ingredient in CFS/ME treatment ${ }^{39}$ ) can be fostered online, and E-treatment should attend to these elements.

Peer-led and patient-led sites can be beneficial for some adolescents with chronic conditions. Clinicians may consider discussing this with young people, as they may be willing to integrate online and offline worlds. Clinicians may lack knowledge, confidence and trust in the internet for health ${ }^{40}$ and training could be useful to address this. This could include training clinicians about the type of sites young people visit; exploring clinicians' views and balancing any negative attitudes with the potential benefits that young people report; and exploring ways clinicians can open up conversation about internet use.

Acknowledgements We would like to thank all the participants who took part in the study. We are grateful for the support of the clinicians at the specialist paediatric CFS/ME service at the Royal United Hospitals who helped to identify and recruit participants.

Contributors $A B$ conceptualised the study. $A B, E C$ and $J B$ designed the study. $A B$ collected data and analysed all the data. LB and RMP contributed to data analysis. All authors contributed to the interpretation of the data. AB drafted the article, and all authors reviewed and critically revised it, made important intellectual input and approved the final version.

Funding EC is funded by the National Institute for Health Research (Senior Research Fellowship, SRF-2013-06- 013). RMP was funded by a University of Bristol Scholarship.

Disclaimer The views expressed in this publication are those of the authors and not necessarily those of the NHS, the National Institute for Health Research or the Department of Health.

Competing interests EC was the medical advisor for the Association of Young People with ME (AYME), until 2017. EC is an unpaid medical advisor for the Sussex \& Kent ME/CFS Society.

Patient consent We obtained written consent/ assent from participants.

Ethics approval This study obtained ethical approval from the NHS Research Ethics Committee (15/06/2017, 15/NW/0502).

Provenance and peer review Not commissioned; externally peer reviewed.

Open access This is an open access article distributed in accordance with the Creative Commons Attribution Non Commercial (CC BY-NC 4.0) license, which permits others to distribute, remix, adapt, build upon this work non-commercially, and license their derivative works on different terms, provided the original work is properly cited, appropriate credit is given, any changes made indicated, and the use is non-commercial. See: http://creativecommons.org/licenses/by-nc/4.0/.

\section{REFERENCES}

1. Nijhof SL, Maijer K, Bleijenberg G, et al. Adolescent chronic fatigue syndrome: prevalence, incidence, and morbidity. Pediatrics 2011;127:e1169-75.

2. Crawley EM, Emond AM, Sterne JA. Unidentified Chronic Fatigue Syndrome/myalgic encephalomyelitis (CFS/ME) is a major cause of school absence: surveillance outcomes from school-based clinics. BMJ Open 2011;1:e000252.

3. Crawley E, Hughes R, Northstone K, et al. Chronic disabling fatigue at age 13 and association with family adversity. Pediatrics 2012;130:e71-9.

4. Chalder T, Goodman R, Wessely S, et al. Epidemiology of chronic fatigue syndrome and self reported myalgic encephalomyelitis in 5-15 year olds: cross sectional study. BMJ 2003;327:654-5.

5. Nice. Chronic fatigue syndrome/myalgic encephalomyelitis (or encephalopathy): diagnosis and management of CFS/ME in adults and children (NICE guidelines CG53). London, 2007:CG53.

6. A report of the CFS/ME working group. A report to the chief medical officer of an independant working group 2002.

7. Patel MX, Smith DG, Chalder T, et al. Chronic fatigue syndrome in children: a cross sectional survey. Arch Dis Child 2003;88:894-8.

8. Garralda ME, Rangel L. Impairment and coping in children and adolescents with chronic fatigue syndrome: a comparative study with other paediatric disorders. J Child Psychol Psychiatry 2004;45:543-52.

9. Parslow R, Patel A, Beasant L, et al. What matters to children with CFS/ME? A conceptual model as the first stage in developing a PROM. Arch Dis Child 2015;100:1141-7.

10. Brodie M, Flournoy RE, Altman DE, et al. Health information, the Internet, and the digital divide. Health Aff 2000;19:255-65.

11. How young people use the Internet for health information. Public Health Rep 2001;116:627. 
12. Winzelberg A. The analysis of an electronic support group for individuals with eating disorders. Comput Human Behav 1997;13:393-407.

13. Kisely SR. Treatments for chronic fatigue syndrome and the Internet: a systematic survey of what your patients are reading. Aust N Z J Psychiatry 2002;36:240-5.

14. Wright B, Williams C, Partridge I. Management advice for children with chronic fatigue syndrome: a systematic study of information from the internet. Ir J Psychol Med 1999;16:67-71.

15. Gray NJ, Klein JD, Noyce PR, et al. The Internet: a window on adolescent health literacy. J Adolesc Health 2005;37:243.e1-243.e7.

16. Compas BE, Jaser SS, Dunn MJ, et al. Coping with chronic illness in childhood and adolescence. Annu Rev Clin Psychol 2012;8:455-80.

17. Schmidt S, Petersen C, Bullinger M. Coping with chronic disease from the perspective of children and adolescents--a conceptual framework and its implications for participation. Child Care Health Dev 2003;29:63-75.

18. Moos RH. Life stressors, social resources, and coping skills in youth applications to adolescents with chronic disorders. $J$ Adolesc Health 2002;30(4 Suppl):22-9.

19. Gray NJ, Klein JD, Noyce PR, et al. Health information-seeking behaviour in adolescence: the place of the internet. Soc Sci Med 2005;60:1467-78

20. Coulson NS. Receiving social support online: an analysis of a computer-mediated support group for individuals living with irritable bowel syndrome. Cyberpsychol Behav 2005;8:580-4.

21. Malik SH, Coulson N. The male experience of infertility: a thematic analysis of an online infertility support group bulletin board. $J$ Reprod Infant Psychol 2008;26:18-30.

22. Pkh M, Coulson NS. Exploring the communication of social support within virtual communities: A content analysis of messages posted to an online HIV/AIDS support group. CyberPsychology and Behavior 2008;11:371-4.

23. Bonniface L, Green L. Finding a new kind of knowledge on the HeartNET website. Health Info Libr J 2007;24(Suppl 1):67-76.

24. van Uden-Kraan CF, Drossaert CHC, Taal E, et al. Coping with somatic illnesses in online support groups: Do the feared disadvantages actually occur? Comput Human Behav 2008;24:309-24.

25. Mo PK, Coulson NS. Exploring the communication of social support within virtual communities: a content analysis of messages posted to an online HIV/AIDS support group. Cyberpsychol Behav 2008;11:371-4.
26. White G. Patients tole to stop using 'Dr Google' and go to GP: Independent.ie, 2017.

27. Ahluwalia S, Murray E, Stevenson F, et al. 'A heartbeat moment': qualitative study of GP views of patients bringing health information from the internet to a consultation. $\mathrm{Br} J$ Gen Pract 2010;60:88-94.

28. Malterud K, Siersma VD, Guassora AD. Sample size in qualitative interview studies: guided by information power. Qual Health Res 2015.

29. Braun V, Clarke V. What can "thematic analysis" offer health and wellbeing researchers? Int J Qual Stud Health Well-being 2014:9:26152.

30. Hareide L, Finset A, Wyller VB. Chronic fatigue syndrome: a qualitative investigation of young patient's beliefs and coping strategies. Disabil Rehabil 2011;33:2255-63.

31. Gallant MP. The influence of social support on chronic illness selfmanagement: a review and directions for research. Health Educ Behav 2003;30:170-95.

32. Martz EL H. Coping with chronic illness and disability: theoretical, empirical, and clinical aspects. Boston, MA: Springer US, 2007.

33. Taylor RM, Gibson F, Franck LS. The experience of living with a chronic illness during adolescence: a critical review of the literature. J Clin Nurs 2008;17:3083-91.

34. Behavioral approaches to chronic disease in adolescence. New York, NY, US: Springer-Verlag, 2009.

35. Christian BJ, D'Auria JP. The child's eye: memories of growing up with cystic fibrosis. J Pediatr Nurs 1997;12:3-12.

36. Woodgate RL. Adolescents' perspectives of chronic illness: "it's hard". J Pediatr Nurs 1998;13:210-23.

37. Crawley EM. Internet-based cognitive behavioural therapy (FITNET) is an effective treatment for adolescents with chronic fatigue syndrome. Arch Dis Child Educ Pract Ed 2012;97:238.

38. Nijhof SL, Bleijenberg G, Uiterwaal CS, et al. Effectiveness of internet-based cognitive behavioural treatment for adolescents with chronic fatigue syndrome (FITNET): a randomised controlled trial. Lancet 2012;379:1412-8.

39. Deale A, Wessely S. Patients' perceptions of medical care in chronic fatigue syndrome. Soc Sci Med 2001;52:1859-64.

40. Hale K, Capra S, Bauer J. A framework to assist health professionals in recommending high-quality apps for supporting chronic disease self-management: illustrative assessment of type 2 diabetes apps. JMIR Mhealth Uhealth 2015;3:e87. 